\title{
Immigrant Identity and Experiences in U.S. Higher Education Research: A Systematic Review
}

\author{
Chrystal A. George Mwangi \\ George Mason University \\ U.S. A. \\ Koboul Mansour \\ University of Massachusetts Amherst \\ U.S. A. \\ Mujtaba Hedayet \\ University of Massachusetts Amherst \\ U.S. A.
}

ABSTRACT: As immigrant students continue to enter U.S. education at growing rates, it has become increasingly important for researchers, practitioners, and policymakers to understand these students' pathways into and through college as well as the factors impacting their success. Using a systematic review, this analysis provides a comprehensive understanding of how global mobility shapes and is shaped by U.S. higher education, particularly in how immigrant identity and immigrants' experiences are depicted in U.S. higher education scholarship.

KEYWORDS: Immigrants, higher education, identity, access, persistence

\author{
Conceptual Framework \\ Research Design \\ Findings \\ Visual Presentation \\ References \\ Author Contact
}

By 2050, nearly one in every five United States residents will be foreign born and one in three will be the child of immigrants (Passel \& Cohn, 2008). Immigrants' children are the fastest growing segment of the U.S. child population and, as a result, the proportion of immigrant students in U.S. schools and colleges is increasing rapidly (Portes \& Fernandez-Kelly, 2008). Given that immigrants and their children will continue to comprise a significant proportion of the U.S. population, their educational attainment and occupational success plays a crucial role in the U.S. talent pool. 
Through a systematic integrative review, we illuminate the growing scholarship emphasizing the diverse populations of immigrants seeking access into and through college, which can help better inform research, policy, and practice. While scholars find that immigrants and their children experience differences in the process of educational attainment as compared to native-born students (Baum \& Flores, 2011; Portes \& Fernandez-Kelly, 2008), our review brings the many disparate studies on immigrants' educational experiences into a connected view. Considering the diversity, growth, and importance of immigrant students in U.S higher education, synthesizing scholarship on this student population provides a collective and deeper understanding of their experiences that could not be found within a single study. Using Kim's and Diaz's (2013) social-ecological model for immigrant students, our analysis of the literature develops a comprehensive understanding of how immigrant students are depicted within U.S. higher education scholarship and elucidates how scholars shape research on immigrants' experiences. This integrative review was guided by the following questions:

How are immigrant students' experiences in U.S. higher education presented/depicted within the US higher education scholarship?

How do authors depict societal structures and systems impacting the experiences of immigrant students within the U.S. higher education system?

\section{Conceptual Framework}

Our analysis is framed using Kim's and Diaz's (2013) social-ecological model for immigrant students that is adapted from Bronfenbrenner's (1979) ecological systems theory. Bronfenbrenner (1979) theorized that contexts are embedded within structures (e.g., historical, political, economic, cultural, and institutional), and these structures contribute to the shaping of individuals' learning and identity directly and indirectly. While there are multiple factors that might hinder or benefit students' experiences into and through college, being an immigrant adds another layer of complexity. Kim's and Diaz's (2013) framing of social ecology is particularly relevant to understanding immigrant students because it considers multiple systems and contexts, and also in what ways structural, contextual, identity, and other related factors impact higher education experiences of immigrant students. Specifically, they highlight nested and interrelated structures related to individual immigrants and their microsystems (e.g., family, peers), mesosystems (relationship between microsystems), exosystems (e.g., policy issues), and macrosystems (e.g., values and social forces). We use Kim's and Diaz's (2013) framework to investigate the multiple individual, institutional, and sociocultural factors impacting the experiences of immigrants in U.S. higher education as well to draw conclusions about how immigrants are defined and portrayed in that scholarship.

\section{Research Design}

We use systematic integrative review, which is a procedure for research synthesis allowing for comparison and interpretation of findings from a body of research with diverse methodologies (Torraco, 2005, 2016; Whittemore \& Knafl, 2005). Being able to analyze and integrate research with diverse frameworks and methods was important given that there is not uniformity in how the experiences of immigrant students are studied in higher education, nor a clear affinity for specific methodological approaches within higher education. Integrative reviews are particularly useful for presenting the current and/or 
historical state of a problem, developing theory, and creating implications for policy and practice (Whittemore \& Knafl, 2005). Specifically, we used Whittemore and Knafl's (2005) five-step process for integration, which involves problem identification, literature search, data evaluation, data analysis, and presentation.

\section{Procedures and Inclusion Criteria}

First, we searched 41 of the 51 journals identified by Bray and Major (2011) in their study of journal prestige within the field of higher education (see Table 1 for list of journals).

\section{Table 1}

\section{List of Higher Education Journals}

- Assessment and Evaluation in Higher Education

- College Teaching

- Community College Journal of Research and Practice

- Community College Review

- Higher Education

- Higher Education: Handbook of Theory and Research

- Higher Education Management and Policy

- Higher Education Policy

- Higher Education Quarterly

- Innovative Higher Education

- International Journal of Sustainability in Higher Education

- Journal of College Counseling

- Journal of College Student Retention

- Journal of College Teaching and Learning

- Journal of Computing in Higher Education Internet and Higher Education

- Journal of Continuing Higher Education

- Journal of Diversity in Higher Education

- Journal on Excellence in College Teaching

- Journal of Further and Higher Education

- Journal of General Education

- Journal of Higher Education

- Journal of Higher Education Policy and Management

- Journal of Hispanic Higher Education

- Journal of Marketing for Higher Education

- Journal of Student Affairs Research and Practice

- NACADA Journal

- New Directions for Adult \& Continuing Education

- New Directions for Community Colleges

- New Directions for Higher Education

- New Directions for Institutional Research

- New Directions for Student Services

- New Directions for Teaching \& Learning

- Planning for Higher Education

- Quality in Higher Education 
- Review of Higher Education

- Research in Post-Compulsory Higher Education

- Research in Higher Education

- Studies in Higher Education

- Teaching in Higher Education

- Tertiary Education and Management

Nine journals were excluded due to our inability to gain access to the journal or the inability to search the journal's database using our search procedures. These journals include College \& University, College Student Affairs Journal, Perspectives on the History of Higher Education, Continuing Higher Education, Thought \& Action, Journal of Faculty Development, Journal of College Orientation and Transition, Journal of Applied Research in Community College, and Journal of the Professoriate. It is difficult to ascertain what impact their omission might have had on our review, but in naming the journals we provide more transparency and increase transferability of our process.

We went to each journal's website and first searched for the term "immigrant" and then the term "immigration" in their article search engine. Given our interest in reviewing contemporary scholarship, we only included articles published between 2000-2016. After we removed duplicate articles for each journal search, we retrieved 1,633 articles for further review. The inclusion criteria for the final sample were: (1) higher education context within U.S.; (2) article is based on an empirical study (3); article emphasizes immigrant students and higher education (4); and context of findings, results, or themes addresses immigrants' experiences with U.S. higher education. We did not engage in our search with a predetermined definition of the term "immigrant" but instead included all scholarship that named immigrant students as the focus of their research regardless of how they defined the term immigrant. This approach provided a larger sample of articles to include in our review. We discuss ways in which the articles defined who an immigrant is as well as which immigrant populations were present and absent across the literature in the subsequent Sample section. Articles that met the inclusion criteria were evaluated to ensure that the research design choices made within a study aligned with the stated purpose of the study and methodology selected as well as whether mechanisms for data quality were addressed.

\section{Sample}

From the 1,633 studies retrieved through the literature search, 167 articles met the inclusion criteria and data evaluation. The majority of studies excluded were due to publication type (documents were literature reviews or other non-empirical syntheses), because they did not focus on immigrant students (e.g., focused on immigration policy broadly), or because they did not discuss procedures for maintaining data quality (e.g., validity in quantitative studies, trustworthiness in qualitative studies).

The research methods employed in the studies we reviewed predominantly included qualitative, quantitative, and mixed methods. Although far fewer in number, scholars also used action research and archival data. The most commonly used qualitative methods were individual interviews and focus groups. While most qualitative scholars used a general qualitative approach, some named specific methodologies 
including narrative inquiry, counter storytelling, life history, and critical narratives; ethnography; phenomenology; grounded theory; and case study. The most commonly used quantitative methods were survey research and secondary data analysis. Scholars using secondary data analysis focused on either national data sets or institutional-level data sets. Regression, including multinomial logistic and hierarchical, was the most commonly used form of quantitative analysis, followed by structural equation modeling.

Although we did not use a prescribed definition of immigrant within our inclusion criteria, all of the articles shared in common a focus on individuals who had a history of migration from another country into the United States with the intent of living permanently in the United States. Some articles differed in terms of whether they focused on individuals who themselves migrated from abroad (first generation) or individuals born in the U.S. whose connection to migration was based on their parents or grandparents moving from abroad to the U.S. (second and third generation respectively). Most studies that disaggregated by generation status focused on first and second-generation students (Uy et al., 2016), with five also including third-generation immigrant students (Maramba \& Museus, 2013). Scholars also included immigrant students with various types of documentation statuses and reasons for entry into the United States, including undocumented students (Flores, 2009; Lauby, 2017; Stebleton \& Aleixo, 2015). Because scholars used intended permanency in the United States in their definitions, international students were not included as immigrants across the studies reviewed.

While diversity among immigrant students exist in U.S. higher education, representation of these students was uneven in the literature. For example, undocumented immigrant students were well represented in the articles we reviewed (e.g., Flores \& Horn, 2010; Lauby, 2017; Stebleton \& Aleixo, 2015). Articles focused on immigrant students from specific regions often emphasized Latin America (Nuñez \& Kim, 2012), Southeast Asia (Uy et al., 2016), and Asia Pacific (Inkelas, 2003) students. Immigrant students from particular countries included students originating from Mexico (e.g., Aguayo, et al., 2011; Cerezo et al., 2009; Muñoz, 2012;), Philippines (Maramba \& Museus, 2012), Dominican Republic (Morales, 2009), China (Kim, 2014), Korea (Kim, 2009), El Salvador (Tierney, 2013), Cuba, and Puerto Rico (Nuñez \& Kim 2012).

Researchers also studied the experiences of immigrant students based on their race and ethnicity. Most of the studies we reviewed focused on the experiences of Hispanic/Latinx students, and within those studies, the majority nationality represented was Mexican (Leinbach \& Bailey, 2006; Mahaffy \& Pantoja 2012; O'Connor et al., 2009). Student populations from other racial and ethnic backgrounds present in the literature we reviewed are Black students from outside the U.S. (Griffin et al., 2016; Hope et al., 2016), including Black Caribbean college students (Sanchez, 2013), as well as Asian (Chang \& Chang, 2004), Asian American and Pacific Islander children of immigrants (Laanan \& Starobin, 2004), and Southeast Asian students (Uy et al., 2016).

Some immigrant student populations are understudied or absent in the literature. For instance, only one study specifically focused on the experiences of immigrant graduate students (Espinoza, 2010). The same is true with refugees and asylees. Some other identities are discussed, but not emphasized. For example, gender is discussed, but articles did not tend to focus on a particular gender identity. Also, some researchers 
have aggregated first- and second-generation immigrants. Other immigrant student populations not covered in the literature include affluent students, students with disabilities, queer students, religious students, and students at elite institutions.

\section{Analysis}

Our research team annotated each article's purpose, theoretical framework, methodology/methods, and key findings. Next, team members used a checklist to analyze the articles' concepts and content. The checklist included questions such as: What are the demographic characteristics of the immigrants discussed within the study? How does the article discuss the outcomes of immigrants' engagement with U.S. higher education? For each article, team members responded to the questions, providing evidence from the article to support responses. We next engaged in an analysis of how themes appeared across the articles. Team members wrote memos summarizing the major themes as well as gaps across the articles regarding topics, conceptual frameworks, and methods/methodologies used across the articles; ways in which immigrant students are represented (e.g., demographics present/absent, educational experiences, and supports and barriers in educational experiences); and ways in which systems within Kim's and Diaz's (2013) social-ecological model for immigrant students are reflected/absent. These memos were used to develop the findings, which emerged as the nuanced ways in which educational context, family/community, and policies impact the higher education experiences of immigrants.

There were three researchers involved in the data analysis and we engaged in multiple ways of seeing the data, which mitigated selective perception and elucidated gaps in analysis that might otherwise not be apparent with only one researcher (Denzin, 1978). We sought to enhance the trustworthiness of our data by engaging in reflexive practices throughout the project (e.g., intentionally documenting in our individual analytic notes how our own perspectives may be impacting our interpretations of data, reviewing one another's notes, engaging in reflexive dialogue about how our perspectives may impact our interpretations of data individually and as a team) (Maxwell, 2005). We offered feedback to one another as we developed drafts of the findings, engaged in discussions regarding emerging themes, and provided data-based evidence to support interpretations. For example, when members of the research team had divergent interpretations of a finding, we discussed the divergence as a team and team members provided data as evidence to support their analyses. We continued these discussions until our team reached a consensus. We developed and revised our findings through this process in order to communicate an understanding of the data with which all authors agreed and as a form of collaborative analysis. Given that the systematic literature review approach is a number of steps removed from the original analysis of each study and each study has a different context, it can be difficult to synthesize studies together (Whittemore \& Knafl, 2005). This limitation was managed using strategies such as thick, rich description in the review findings and considering alternative interpretations. 


\section{Findings}

Our findings first focus on the question: How are immigrant students' experiences in U.S. higher education presented/depicted within U.S. higher education scholarship? We then use Kim's and Diaz's (2013) social-ecological model for immigrant students to demonstrate how various systems are emphasized within the literature and their impact on the experiences of these students in the U.S. higher education system.

\section{Immigrant Identity and Experiences in U.S. Higher Education}

One of the ways in which we analyzed the literature was to consider how scholars discussed the ways immigrants were perceived and positioned within U.S. higher education. We found that immigrants were positioned both negatively and positively in regard to higher education.

\section{Negative Depictions}

Immigrants were often depicted in negative terms. For example, one of the most prominent themes was related to lacking the knowledge or having the skills needed to effectively navigate (1) the college preparation and choice process in the U.S. and (2) the college experience and achieving college success. Knowledge deficits ranged from lack of information about the college choice process and what is needed to be a competitive college applicant (e.g., Engstrom, 2008; Kouyoumdjian et al., 2017; Lauby, 2017; Leinbach \& Bailey, 2006) to lack of knowledge about resources to help navigate college and requirements for college graduation (Cerezo et al., 2009; Freeman, 2017; Mahaffy \& Pantoja, 2012; Person \& Rosenbaum, 2006). Another major challenge was the lack of English language skills (Conway, 2010; Eberly, 2018; Engstrom, 2008; Smith, 2010). For example, Arbelo-Marerro and Milacci (2016) found that "English language learning played a vital role in the persistence behaviors of participants" (p. 22) who were Latinx nontraditional students enrolled at Hispanic serving institutions.

The second most prominent theme regarding the negative depiction of immigrants focused on their lack of resources needed to effectively navigate (1) the college preparation and choice process in the U.S. and (2) the college experience and achieving college success (Freeman, 2017; Mahaffy \& Pantoja, 2012; Oseguera et al., 2008). O'Connor et al. (2009) discussed the negative impact of limited social capital in some immigrant communities, which leads to lack of information for college and overrepresentation of immigrants in community college. While this theme is similar to and intersects with the first (sometimes being discussed within the same article), there is more of a focus on the individual level (e.g., academic preparedness, college knowledge) within the first theme. Conversely, the second theme focuses on how microsystems around immigrants can lack resources or, due to being immigrants, students are unable to access necessary resources. For example, undocumented students' lack of financial resources for college ties to U.S. public policy and students' inability to qualify for federal financial aid (Flores, 2009; Flores \& Horn, 2010; Herrera et al., 2013; Nienhusser, 2014). Each of these themes connects to scholars focusing on low-income, first generation to college, and/or undocumented immigrant populations within their studies, in which broader social stratification and structural inequalities in the U.S. can negatively impact the educational experiences of these students. 
Although less often discussed in the literature, another prominent theme illustrated the prejudices that immigrant groups can experience in the U.S., which also had a negative impact on their higher education experience. This included racism, xenophobia, and nativism (Chang, 2017; Mendez \& Cabrera, 2015) and was a theme often highlighted in scholarship on the experiences of undocumented students (Cadenas et al., 2018; Flores, 2009; Person et al., 2017; Southern, 2016). While these forms of prejudice could be blatant, they were also present in less direct ways through academic invalidation (Acevedo-Gil et al., 2015), cultural invalidation by dominant university culture (Museus \& Maramba, 2011), and educators reifying the model minority myth (Kim, 2014). Scholars also discussed immigrants' educational and occupational outcomes being correlated to a racist and/or nativist U.S. society (Flores \& Southern, 2010; Kim, 2003). Immigrant students from the Caribbean and Africa experienced racial marginalization within the U.S. education system (Tauriac \& Liem, 2012). Sanchez (2013) found that Black students of Caribbean origins believed that detaching themselves from their ethnic culture and racial background would help them assimilate to the dominant white culture in the US, which they perceived would boost their chances to succeed.

\section{Positive Depictions}

Conversely, scholars also discussed a number of positive depictions of immigrants in U.S. higher education. For example, for many immigrant populations, there is a focus on family and community, which gives students a strong network of emotional support and motivation (Chlup et al., 2018; Morales et al., 2011; Pena et al., 2007; Perez et al., 2010). Scholars who discussed this benefit referred to concepts like familismo, familism, and filial responsibility (Del Pilar, 2009; Espinoza, 2010; Rudolph et al., 2011). Interestingly, this theme presents a different lens of immigrant students' social networks than the previous theme, which focused on students lacking resources in their homes and communities. Instead, this theme demonstrates that financial support or cultural capital are not the only means of one's microsystem positively contributing to the higher education experience (Diaz-Strong et al., 2011; Easley et al., 2012; Luna \& Prieto, 2009; Morales et al., 2011). Further, scholars discussed how the value of community for some immigrants led them to be proactive in seeking out social networks needed to support their college access and persistence, which reinforced their success (Mahaffy \& Pantoja, 2012; Person \& Rosenbaum, 2006; Riegle-Crumb, 2010).

Another way in which scholars described immigrants positively within the U.S. higher education context was by demonstrating that this population often has high levels of motivation and resilience, despite structural inequalities and other barriers that they face in pursuing higher education (De La Cruz, 2008; Luna \& Prieto, 2009; Morales et al., 2011; Tauriac \& Liem, 2012). Similarly, articles focused on college access discussed immigrants having high college going and career aspirations (Arbelo-Marrero \& Milacci, 2016; Griffin et al., 2012). This was linked to the concept of immigrant optimism and the desire for social mobility that could act as a protective factor against challenges within the U.S. education system (Sanchez, 2013; Thorstensson Davila, 2008).

Related to both of these themes (i.e., positive benefits of social networks and having academic motivation and resilience), scholars framed their discussion of immigrants through the concept of culture, discussing the cultural assets and pride that 
immigrants bring to their higher education experience (Mahaffy \& Pantoja, 2012; Tierney, 2013). Frameworks like community cultural wealth were used to highlight the knowledge, resources, and skills that immigrants have, and which can often go unacknowledged and unreinforced in U.S. educational environments (Kouyoumdjian et al., 2017; Tierney, 2013). The final theme focused on activism and advocacy (Luna \& Prieto, 2009; Morales et al., 2011; Pena et al., 2007; Perez et al., 2010). A few scholars demonstrated how being an immigrant alongside experiencing challenges and oppression in U.S. higher education led some students to become activists for greater educational and other forms of equity for their immigrant communities (Deangelo et al., 2016; Madrigal-Garcia \& Acevedo Gil, 2016; Mendez \& Cabrera, 2015).

\section{Immigrant Heterogeneity}

One theme that does not fall into a positive or negative depiction is that scholars throughout our dataset discussed that having an immigrant identity should not be viewed homogenously. Factors such as race, country of origin, citizenship status, generation status, etc. can all have varying impacts on how immigrants view and experience U.S. higher education (Becerra, 2010; Garcia \& Bayer, 2005; Griffin et al., 2016; Nuñez, 2009). Many of the aforementioned themes on positive and negative depictions focus on lowincome and first-generation to college immigrants. While it is important that researchers emphasize the needs of those particular immigrant populations given the educational inequities that they face, it is important to also understand these are not the only immigrant groups with a presence in the U.S. higher education system. Further, scholars discussed students having intersected, bicultural, and/or hybridized identities that complicate how one's multiple identities interact to impact their educational experience, as well as how identities are not static, but can shift and change within different environments (e.g., moving from K-12 to higher education; moving from home country to the U.S.) (Aguayo et al., 2011; McLaughlin et al., 2008; Pyne \& Means, 2013).

\section{Structures \& Systems Impacting Immigrants' Higher Education Experiences}

Our analytical framework is based on Kim's and Diaz's (2013) social-ecological model for immigrant students. Therefore, it is important to look at how different systems and structures appeared in the literature on the postsecondary experiences of immigrant students.

\section{Microsystem}

Although the microsystem is one of the smallest units within the other systems, it is also very complex as it comprises dynamic, interactive, and interrelated structures. Our analysis illustrates family as an essential microsystem structure in the educational experiences of immigrant students. In the literature, the different roles the family played in defining the college experiences of immigrant students were widely discussed. For example, the academic achievement and college experience of Chinese and Korean immigrant college students are highly influenced by their parents' expectations and families that value academic success, viewing academic success as key to social and economic mobility (Kim, 2014). Also, studies showed that families of immigrant students are generally supportive of their education and are a main source of emotional and financial support, as well as aspirational and resistant capitals (Diaz-Strong et al., 2011; Easley et al., 2012; Luna \& Prieto, 2009; Morales et al., 2011). Pyne and Means (2013) 
found that family support for Hispanic students is one of the key factors that helps them overcome some of the institutional and systematic barriers they face on campus.

While studies showed that the family can be a main factor and tool for success and overcoming challenges, there is also a body of literature revealing that family can be a barrier (Fann et al., 2009; O'Connor et. al., 2009). For example, immigrant students whose parents are foreign born receive significantly less parental academic support/involvement compared to their peers with at least one parent who was born in the U.S. (Wolf et al., 2009). Furthermore, gaining information about college is challenging for students when their parents do not have a college degree (Chlup et.al., 2018). Differences in cultural expectations between home and school, as well as how gender roles play into different environments can create tensions within families (Castillo et al., 2012; Rudolph et al., 2011; Sy \& Romero, 2008).

In Kim's and Diaz's (2013) definition of microsystems, they refer to roles as the "expected actions on the level of the individual as well as that of the wider society" (p. 28) and to interpersonal relationships as "how people treat each other when they are together" (p.28). This definition is in alignment with how literature reflected the roles of higher education staff and faculty in shaping the academic and nonacademic experiences of immigrant students. Immigrant students face cultural barriers on the institutional level in relation to their adjustment on college campuses due to the lack of understanding of their cultural experience (Museus \& Maramba, 2011), lack of diversity in predominantly white institutions (Griffin et al., 2016), and experiencing negative campus climate and racial discrimination (Cress \& Ikeda, 2003; Hope et al., 2016). For example, Asian immigrant students struggle with their adjustment on college campuses due to the lack of understanding of their cultural experience (Museus \& Maramba, 2011). In the same vein, Griffin et. al (2016) found that Black immigrant students are frustrated with the lack of racial diversity in predominantly white institutions. Additionally, Sullivan et al. (2007) and Cerezo et al. (2009) found that lack of culturally-relevant and/or targeted efforts from campus counseling services to serve immigrant students undermined their college experience. Cress and Ikeda (2003) found that experiencing negative campus climate has a substantial negative impact on Asian immigrant college students' mental health and that it is a strong predictor of depression. Support received from faculty, staff members, and student affairs professionals is one of the main predictors of a positive college experience for immigrant students (Chang, 2005; Chen \& Rhoads, 2016). Stebleton and Aleixo (2015) highlighted that validating behaviors from faculty and institutional agents greatly mattered for undocumented students who face unique challenges due their undocumented status. Morales (2009) investigated the role of staff and faculty on immigrant students' academic progress, academic standing, and retention, finding that "the mentors proved to be valuable social capital for these statistically at-risk students by providing them with insider academic information, legitimizing their academic and professional goals, and transforming their immigration experiences into academic inspiration" (p. 385).

Immigrant students' engagement in various forms of activism on campuses yielded two different outcomes in connection with peer relationships (Deangelo et al., 2016). In one of the few articles focused on peers, Herrera et al. (2013) found that undocumented immigrant students face prejudice from their U.S. citizen peers on campus due to their 
immigration status. In contrast, Nuñez (2009) found that Latino students who are actively engaged in campus life have a higher sense of exclusion because they develop a sense of consciousness that raises their awareness about racial issues that exist on campus and in society at large. Scholars, also, discussed how peers could be a pivotal source of support (Pak, 2018; Smith, 2010). Still, the role of peers was one of the least discussed relationships on the microsystem level within the literature.

\section{Mesosystem}

Another system on the social-ecological model for immigrant students is the mesosystem, which refers to the interactions and relationships between the microsystems (Kim \& Diaz, 2013). Arana et al. (2011) discussed how microsystems should interact to more positively impact students, recommending that "universities should create an environment that simultaneously utilizes the familiar cultural and familial connections and alleviates the pressures arising from the student context" (248). In the same vein, Gonzales et al. (2003) emphasized the significance of the interaction between the different microsystems to foster student access. Auerbach (2004) and Fann et al. (2009) present examples of this by investigating the critical role of creating partnerships between parents of college going students, outreach programs, and schools.

While fostering interactions and relationship among the various microsystems positively influences immigrant students' postsecondary experiences, it can also create tensions. Alexander et al. (2007) and Becerra (2010) discussed the incongruence between the Hispanic community and PWI environment, especially in terms of linguistic acculturation and level of clarity regarding the U.S. higher education system. As a result, scholars like Eberly (2018) concluded that "there is a strong need for culturally responsive education support services in languages understood by students" (p. 16).

Although the mesosystem elucidates the relationships between the microsystems, students are often the bridge between their microsystems (like family and school), rather than the microsystems interacting themselves. For example, when Person et al. (2017) examined immigrant students' aspirations in comparison with what they believed they could actually achieve, they found that undocumented students are resilient; however, they had internal conflict between how they saw themselves and how society sees them.

\section{Exosystem}

The next layer on the social-ecological model for immigrant students is the exosystem and, in our analysis, the exosystem was predominantly discussed in the articles as financial aid policy, immigration policy, and institutional policies affecting immigrant students' college experiences. Extant literature demonstrates inequities in information about financial aid that can be critical for immigrant student in their collegegoing process and decisions. For example, findings of a study by Uy et al. (2016) suggest that Southeast Asian immigrant students are less prepared to navigate financial aid in college due to lack of social and capital support compared to their non-immigrant peers. This lack of information has an impact on college choice for immigrant students, as O'Connor et al. (2009) state that, "less access to desirable social capital may result in a lack of adequate information about higher education finances, and that, in turn, may result in college-qualified Hispanic high school graduates applying to community colleges instead of 4-year schools" (p. 215). Financial cost is another reason immigrant students 
are more likely to choose community colleges over four-year institutions. Southern (2016) illuminates that, even with some financial aid, financing education at a four-year institution remains a challenge for many immigrant students, especially those with undocumented status.

We found that in most cases financial aid and immigration policies are intertwined in the literature on immigrant students because students' immigration status determines their eligibility for different types of financial aid programs. Undocumented immigrant students are among the most underserved immigrant students in terms of receiving financial aid due to their status as "they cannot apply for federal or state aid, most scholarships, and even loans; consequently, they are systematically being discarded from the higher education system" (Diaz-Strong et al., 2011, p. 112). A major focus in the literature is on state financial aid for undocumented students as some states have implemented inclusive policies to improve their college access and affordability (Southern, 2016). Tuition policies supporting undocumented students have a positive impact on these students' college enrollment rates. Results of the study by Flores (2009) show a significant increase in college enrollment of undocumented students in states that implement in-state resident tuition (ISRT) policies when comparing with the same student population in states without such tuition benefits.

Researchers also found that states with inclusive policies for immigrant students becomes more attractive for this population. However, in states without such policies, participation of undocumented students in higher education becomes a challenge for both the policy makers and the undocumented students themselves (Flores \& Chapa, 2009). Given the importance of state and institutional policies favoring undocumented students, researchers advocate for the expansion of existing policies and development of new inclusive policies (Nienhusser, 2015). When undocumented students do enroll in college, they cannot pursue all facets of the college experience due to their immigration status (Southern, 2016). Mendez and Cabrera (2015) provide as a specific example an unwelcoming campus climate due to the implementation of excluding policies, explaining that "participants experienced and perceived the campus racial climate at the UA [University of Arizona] following the passages of SB 1070 and HB 2281," which led to racial tension, stress, and fear among undocumented students (p. 39). College campuses may not only be unwelcoming to undocumented students but also to other immigrant students. The findings of a study by Cress and Ikeda (2003) highlight a depressing campus climate for Asian immigrants filled with many stressors where they faced minoritizing, racist, culturally unwelcoming, and immigrant barring experiences affecting their mental health.

Although discussed only briefly in a few studies in our sample, transfer policies and language policies are other institutional policies that can impact the higher education experiences of immigrant students. For example, immigrant students tend to be nonnative speakers of English and, thus, may need English language programs in schools and colleges as remedial education. Proficiency/lack of proficiency in English language determines students' access to college and the type of higher education institution in which they enroll (Flores \& Drake, 2014). However, the need for English language remedial programs in college vary among immigrant students based on their race/ethnicity. Flores and Drake (2014) found that "Hispanic immigrants, both first- and 
second-generation, are more likely to indicate that they have enrolled in a remediation course than their Asian first- and second-generation immigrant counterparts" (p. 4).

\section{Macrosystem}

In analyzing the literature for how a macrosystem connects to immigrants' higher education experiences, we found scholars discussing how economic, political, and historical contexts within the U.S. framed their research studies and findings. The economic context was a predominant theme discussed, specifically connected to the labor market. For example, Flores's and Southern's (2010) study emphasized, "how Latino individuals with a postsecondary degree fare in the U.S. labor market based on their citizenship status within the recent immigration context" (p. 24), and scholars also discussed the importance for more research on the connection between labor market opportunities and the educational attainment of immigrants (Flores \& Chapa, 2009). In connection with the labor market, scholars also discussed how job opportunities are stratified by education level. Kim (2003) highlighted that "one of the most salient trends in the U.S. labor market is the rise in the college versus noncollege earnings gap" (p. 279), but also found that both immigrant status and education level impact job earnings. Similarly, Wrigley et al.'s (2009) study suggested that English language ability and proficiency impact involvement in the labor market. In the literature we reviewed, higher education is connected to the economic context through discourse around the critical need for a well-educated workforce in the U.S. that has moved from an industrial to a technology-driven workforce within the last century (Jauregui \& Slate, 2010; Laanan \& Starobin, 2004). Given this economic context, scholars made connections to the exosystem and the need for U.S. public policy that supports the need for greater college participation by diverse populations, including immigrants (Flores \& Horn, 2010).

Another major way in which the macrosystem was reflected in the literature was through social forces, which could present competing discourses. For example, we found that articles discussed U.S. society perpetuating racism and nativism as well as being a society that values diversity and multiculturalism. Racism and nativism appeared in how immigrants were treated in the U.S. educational system (Auerbach, 2004; Cress \& Ikeda, 2003; Gonzalez et al., 2003, Pena et al., 2007; Tauriac \& Liem, 2012), as well as being reflected in public policies that then impacted the educational experiences of immigrants (Person et al., 2017). Some immigrant populations resisted being racialized in a U.S. context. Yet, Griffin et al. (2016) demonstrated that this resistance was not always successful by explaining that, "although ethnic differences may initially distinguish Black immigrants from native Blacks, research suggests that the system of racial stratification in the U.S. imposes expectations and stereotypes based on racial identity" (p. 37). Conversely, the value of diversity and multiculturalism were discussed extensively related to higher education curriculum (Luna \& Prieto, 2009; Nuñez, 2009; Teranishi, 2007), as well as in universities striving to recruit and retain students of diverse backgrounds, including immigrant students (Museus \& Maramba, 2011; Oseguera et al., 2008; Wolf et al., 2009). Scholars supported the importance of diversity and multiculturalism being reflected in U.S. higher education (Fann et al., 2009). It seemed that both the forces of nativism and racism, as well as diversity and multiculturalism, play a predominant role in how U.S. society functions, which ultimately impacts how individuals navigate U.S. educational spaces. 
Another more underlying social force that directly ties to the immigrant experience relates to the concept of the American Dream and belief in a meritocracy. Scholars discussed and critiqued these concepts (e.g., Garibay et al., 2015; Morales et al., 2011). For example, one of Morales et al.'s (2011) findings was called "the land of opportunity and denial" (p. 273) because it demonstrated both how immigrants were messaged that success was possible for anyone in the U.S., while simultaneously being denied a number of opportunities related to social mobility. Still, it was clear that these concepts informed how some immigrants saw educational opportunity in the U.S. and how educational opportunity was framed in the U.S.

Although discussed to a lesser extent, researchers also focused on political and historical contexts that shape immigrant students' experiences with higher education in the U.S. Political connections related to democratic ideology and the role of citizenship and civic engagement (e.g., Muñoz, 2012; Perez et al., 2010). However, Perez and colleagues (2010) allude to a greater need to focus on the political context, stating, "In this age of globalization, when traditional conceptions of the nation-state and national identification are changing rapidly, identifying the factors that determine or contribute to a person's identification and allegiance to a given state or society (or alternatives) is crucial" (p. 261). Although policy issues are discussed to some extent in the literature we reviewed, a macrostructural examination of the political system and ideologies in the U.S., as well as how the political context impacts immigrants, was limited.

Similarly, historical contexts were referenced within the articles, but there was less of an emphasis of how the past impacts present day immigrant experiences with higher education. Authors that referenced this context did so through discussing the historical context of immigration in the U.S. (Flores, 2009; McLaughlin Gonzalez et al, 2008; Pena et al., 2007) or the historical context of particular public policies such as DREAM Act initiatives (e.g., DeAngelo et al., 2016; Diaz-Strong et al., 2011). Scholars who emphasized the historical context often used it to elucidate the reproduction of inequality that immigrant populations have experienced within the U.S. education system and U.S. society more broadly.

One issue that Kim and Diaz (2013) did not mention in their interpretation of the macrosystem for immigrants is that, although a dominant U.S. culture exists, immigrants are also still experiencing their home country's cultural norms, expectations, and socialization, which can create tension as well as impact the educational experience. For example, the literature we reviewed demonstrated these tensions relating to different gender expectations between U.S. dominant culture and immigrants' home country culture, and tensions between an individualistic worldview found in U.S. dominant society and a collectivistic or familistic worldview found in many immigrant communities (e.g., Del Pilar, 2009; Diaz-Strong et al., 2011; Espinoza, 2010; Rudolph et al., 2011). Individual immigrants have to navigate both U.S. macrosystem forces regarding cultural expectations but may have been previously socialized within other countries with different macrosystem cultural expectations or are being socialized around these home country expectations within the U.S. in their homes or cultural enclaves (microsystems). Ultimately, scholars, argue that incongruence between cultural expectations has an impact on immigrant students' educational experiences (McLaughlin Gonzalez \& Raymond Ting, 2008). Yet, studies that considered these cultural tensions focused 
predominantly on how individual immigrant students navigated them and not on the macrosystem itself.

\section{Visual Presentation and Discussion}

Given our findings, and Whittemore's and Knafl's (2005) recommendations for the final step in an integrative review as "presentation" of the synthesis of research, we revised Kim's and Diaz's (2013) social-ecological model for immigrant students to reflect our analysis of the extant literature (see Figure 1).

Figure 1

Revised Social-ecological Model for Immigrant Students

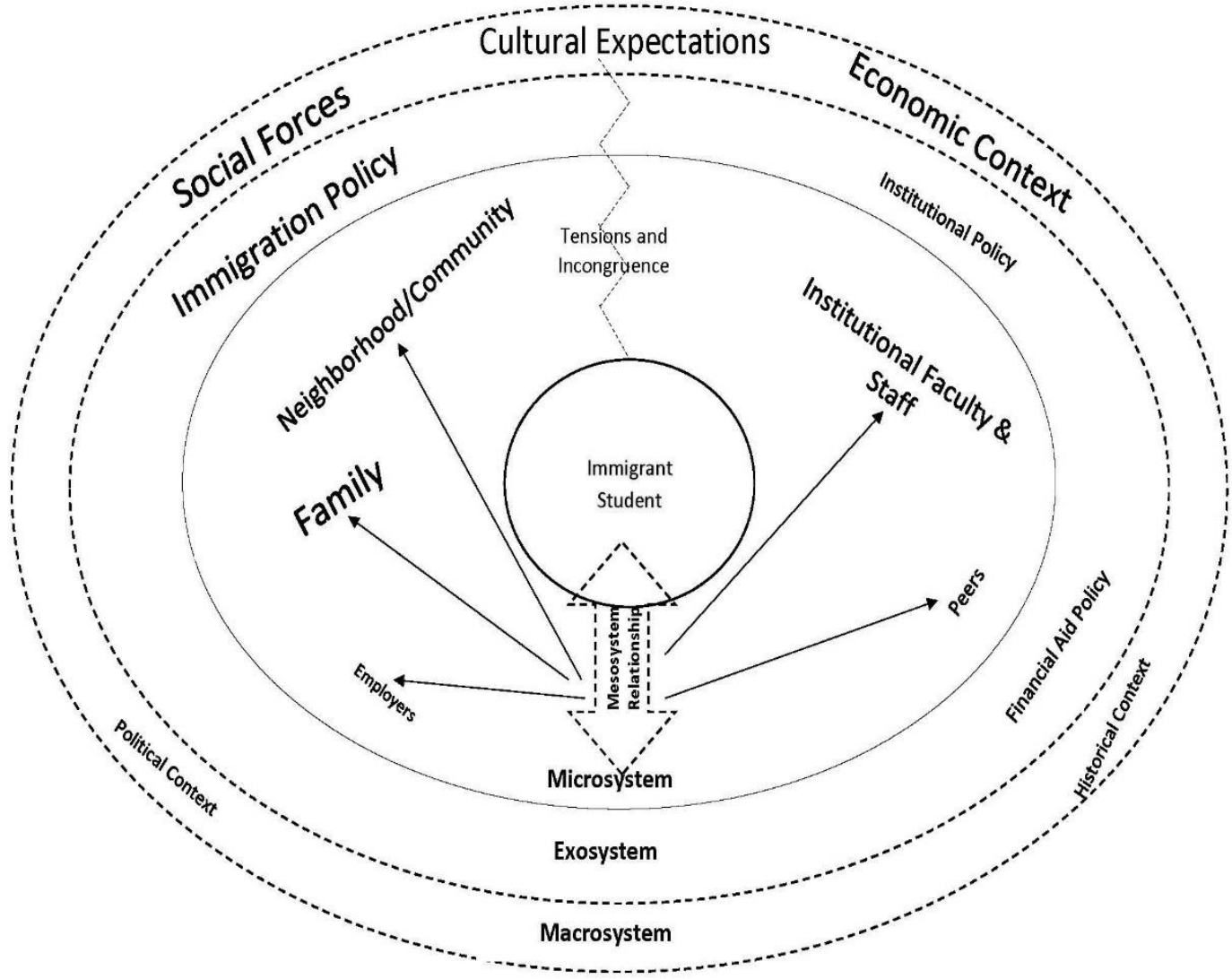

Our findings show that the microsystem is one of the most discussed systems in the literature we reviewed. However, certain structures within that system were more salient than others. The six structures that are included within the microsystem are family, institutional staff, faculty, neighborhood, peers, and employers. Family ranked first as the most analyzed structure on how it impacts immigrant students' higher education 
experiences. Neighborhood/community comes in a close second, which we believe is natural because both family and local community structures are often produced and reproduced by each other. Discussions regarding the role of higher education staff and faculty were often presented together in research and were analyzed as part of institutional efforts to improve and support immigrant students' academic and nonacademic experiences on campus. So, unlike the way they are situated apart from each other in Kim's and Diaz's model, they are connected in the revised model. While peers play a key role in the experiences of immigrant students, whether positively or negatively, this component of the microsystem was seldomly discussed in the literature. Lastly, the discussion about employers was almost nonexistent, which is also reflected in the revised model.

The mesosystem in Kim's and Diaz's (2013) original model is referred to as a twoway arrow that reflects the interactions among the microsystems. However, the synthesis of studies reviewed suggests that interactions at this level are facilitated through interactions between the student and the various microsystem structures. Accordingly, in our revised visual, the dotted-lined double arrow between the immigrant student and the mesosystem reflects the facilitation of this process. Moreover, this dynamic is also represented through the other dotted lines that connect the structures within the microsystem to the immigrant student and the mesosystem.

In our analysis we found that the exosystem is under-researched in the literature with a few exceptions. While the exosystem includes financial aid policies, immigration policies, institutional policies, and parental work environment (Kim \& Diaz, 2013), not all components of these policies are researched and discussed in the literature. The literature on financial aid only discusses in-state resident tuition policies for undocumented students (ignoring other financial aid policies for immigrant students); immigration policies only discuss undocumented students and/or DACA students; and institutional policies only briefly discuss some language and transfer policies and some other policies shaping the campus climate for certain groups of immigrant students. Parental work environment is not discussed at all. Therefore, the exosystem band in the visual is slimmer than the microsystem but slightly bigger than the macrosystem in our revised model.

The macrosystem is one of the more under-researched systems within extant literature. Although the macrosystem is often discussed across studies as a factor to be acknowledged, it is rarely the focus of empirical inquiry within studies on the educational experiences of immigrants in U.S. higher education. Given the lack of analysis on the macrosystem within extant research, our visual illustrates it as a slimmer band than other systems within the visual. Furthermore, the dotted line reflects that, while the macrosystem is present within the literature, it is often included as a peripheral factor. While social forces, cultural expectations, and economic context are the most discussed forms of macrosystem factors within the literature (reflected in the visual by their large font size), political and historical contexts are also present, but to a lesser extent (reflected in the visual by their small font size). We also highlight in the visual how dominant U.S. macrosystem forces are often demonstrated as being in tension with individual immigrant cultural worldviews and values. 
Our visual representation and analysis are constrained by the research that exists. Specifically, most of the immigrant-focused research that exists within the journals we searched focused on Latinx immigrant students, specifically from Mexico. This is not surprising because of Mexico's proximity to the U.S (sharing a long border), which makes it the number one country of origin for immigrants in the United States. However, care must be taken in interpreting our findings and its applicability to diverse immigrant populations. Due to researcher sampling decisions related to search terms and strategies, as well as inclusion/exclusion criteria, it is also possible that some relevant literature was not included in the sample informing our visual representation and analysis.

\section{Conclusion}

In spite of noted limitations, our analysis demonstrates many ways in which scholars have presented immigrants' experiences in the U.S. higher education system. However, we also found that much of this literature presents immigrants as a singular group or sharing a singular experience. While geographic movement into the U.S. may create some shared experiences, immigrants in the U.S. come from many different nationalities, social classes, races/ethnicities, modes of entry, etc. that impact how they are received and perceived in the U.S. and its higher education system. As research on immigrants within U.S. higher education continues to grow, we recommend that scholars disaggregate immigrant research samples to emphasize the diversity present within this population, acknowledge the limitations when data cannot be disaggregated, and center on under researched immigrant populations with a growing presence in the U.S. higher education system (e.g., refugees, asylees, immigrants who are racially Black).

The two least-focused-on components of the ecological system were the exosystem and macrosystem levels. Therefore, we suggest scholars develop more policy-focused and intentionally policy-relevant research related to immigrants and immigration's connection to U.S. higher education. Further, we found that the macrosystem does permeate all other systems emphasized within the research we reviewed and therefore warrants clearer understanding. We recommend that researchers continue to investigate how the macrosystem is impacting factors such as immigrants' experiences within the U.S. higher education system, universities' support of immigrant students, and the development of public policy impacting immigrants in U.S. higher education.

\section{References}

Acevedo-Gil, N., Santos, R. E., Alonso, L., \& Solorzano, D. G. (2015). Latinas/os in community college developmental education: Increasing moments of academic and interpersonal validation. Journal of Hispanic Higher Education, 14(2), 101127. https://doi.org/10.1177/1538192715572893

Aguayo, D., Herman, K., Ojeda, L., \& Flores, L. Y. (2011). Culture predicts Mexican Americans college self-efficacy and college performance. Journal of Diversity in Higher Education, 4(2), 79-89. https://doi.org/10.1037/a0022504

Alexander, B. C., Garcia, V., Gonzalez, L., Grimes, G., \& O'Brien, D. (2007). Barriers in the transfer process for Hispanic and Hispanic immigrant students. Journal of 
Hispanic Higher Education, 6(2), 174-184. https://doi.org/10.1177/1538192706297440

Arana, R., Castaneda-Sound, C., Blanchard, S., \& Aguilar, T. E. (2011). Indicators of persistence for Hispanic undergraduate achievement: Toward an ecological model. Journal of Hispanic Higher Education, 10(3), 237-251. https://doi.org/10.1177/1538192711405058

Arbelo-Marrero, F., \& Milacci, F. (2016). A phenomenological investigation of the academic persistence of undergraduate Hispanic nontraditional students at Hispanic Serving Institutions. Journal of Hispanic Higher Education, 15(1), 22-40. https://doi.org/10.1177/1538192715584192

Auerbach, S. (2004). Engaging Latino parents in supporting college pathways: Lessons from a college access program. Journal of Hispanic Higher Education, 3(2), 125145. https://doi.org/10.1177/1538192703262514

Baum, S., \& Flores, S. M. (2011). Higher education and children in immigrant families. The future of children, 171-193. https://doi.org/10.1353/foc.2011.0000

Becerra, D. (2010). Differences in perceptions of barriers to college enrollment and the completion of a degree among Latinos in the United States. Journal of Hispanic Higher Education, 9(2), 187-201. https://doi.org/10.1177/1538192709359051

Bray, N. J., \& Major, C. H. (2011). Status of journals in the field of higher education. The Journal of Higher Education 82(4), 479-503. https://doi.org/10.1080 /00221546.2011.11777213

Bronfenbrenner, U. 1979. The ecology of human development: Experiments by nature and design. Harvard University Press.

Cadenas, G. A., Cisneros, J., Todd, N. R., \& Spanierman, L. B. (2018). DREAMzone: Testing two vicarious contact interventions to improve attitudes toward undocumented immigrants. Journal of Diversity in Higher Education, 11(3), 1-14. https://doi.org/10.1037/dhe0000055

Castillo, L. G., Zahn, M. P., \& Cano, M. A. (2012). Predictors of familial acculturative stress in Asian American college students. Journal of College Counseling, 15(1), 52-64. https://doi.org/10.1002/j.2161-1882.2012.00005.x

Cerezo, A., O'Neil, M. E., \& McWhirter, B. T. (2009). Counseling Latina/o students from an ecological perspective: Working with Peter. Journal of College Counseling, 12(2), 170-181. https://doi.org/10.1002/j.2161-1882.2009.tb00114.x

Chang, A. (2017). "Call me a little critical if you will:" Counterstories of Latinas studying abroad in Guatemala. Journal of Hispanic Higher Education, 16(1), 3-23. https://doi.org/10.1177/1538192715614900

Chang, J. C. (2005). Faculty student interaction at the community college: A focus on students of color. Research in Higher Education,46(7), 769-802. https://doi.org/10.1007/s11162-004-6225-7 
Chang, T., \& Chang, R. (2004). Counseling and Internet: Asian American and Asian international college students' attitudes toward seeking online professional psychological help. Journal of College Counseling, 7, 140-149. https://doi.org/10.1002/j.2161-1882.2004.tb00245.x

Chen, A. C., \& Rhoads, R. A. (2016). Undocumented student allies and transformative resistance: An ethnographic case study. The Review of Higher Education,39(4), 515-542. https://doi.org/10.1353/rhe.2016.0033

Chlup, D. T., Gonzalez, E. M., Gonzalez, J. E., Aldape, H. F., Guerra, M., Lagunas, B., \& Zorn, D. R. (2018). Nuestros hijos van a la universidad [Our sons and daughters are going to college]: Latina parents' perceptions and experiences related to building college readiness, college knowledge, and college access for their children-A qualitative analysis. Journal of Hispanic Higher Education, 17(1), 2040. https://doi.org/10.1177/1538192716652501

Conway, K. M. (2010). Educational aspirations in an urban community college: Differences between immigrant and native student groups. Community College Review, 37(3), 209-242. https://doi.org/10.1177/0091552109354626

Cress, C. M., \& Ikeda, E. K. (2003). Distress under duress: The relationship between campus climate and depression in Asian American college students. NASPA Journal,40(2). https://doi.org/10.2202/1949-6605.1224

Deangelo, L., Schuster, M. T., \& Stebleton, M. J. (2016). California DREAMers: Activism, identity, and empowerment among undocumented college students. Journal of Diversity in Higher Education,9(3), 216-230. https://doi.org/10.1037/dhe0000023

De La Cruz, Y. (2008). Who mentors Hispanic English language learners? Journal of Hispanic Higher Education, 7(1), 31-42. https://doi.org/10.1177 $/ 1538192707310509$

Del Pilar, J. A. (2009). Mental health and Latino/a college students: A psychological perspective and new findings. Journal of Hispanic Higher Education, 8(3), 263281. https://doi.org/10.1177/1538192708328891

Denzin, N. K. (1978). The research act: A theoretical introduction to sociological methods ( ${ }^{\text {nd }}$ ed.). McGraw-Hill. https://doi.org/10.4324/9781315134543

Diaz-Strong, D., Gomez, C., Luna-Duarte, M. E., \& Meiners, E. R. (2011). Purged: Undocumented students, financial aid policies, and access to higher education. Journal of Hispanic Higher Education, 10(2), 107-119. https://doi.org/10.1177/1538192711401917

Easley, Jr. N., Bianco, M., \& Leech, N. (2012). Ganas: A qualitative study examining Mexican heritage students' motivation to succeed in higher education. Journal of Hispanic Higher Education, 11(2), 164-178. https://doi.org/10.1177 $/ 1538192712440175$

Eberly, J. E. (2018). Community college developmental education services: Perspectives of Spanish-speaking Latino early childhood educators. Journal of Hispanic Higher Education, 17(1), 3-19. https://doi.org/10.1177/1538192716652500 
Engstrom, C. M. H. (2008). Curricular learning communities and unprepared students: How faculty can provide a foundation for success. New Directions for Teaching and Learning, 2008(115), 5-19. https://doi.org/10.1002/tl.322

Espinoza, R. (2010). The good daughter dilemma: Latinas managing family and school demands. Journal of Hispanic Higher Education, 9(4), 317-330. https://doi.org/10.1177/1538192710380919

Fann, A., McClafferty Jarsky, K., \& McDonough, P. M. (2009). Parent involvement in the college planning process: A case study of P-20 collaboration. Journal of Hispanic Higher Education, 8(4), 374-393. https://doi.org/10.1177/1538192709347847

Flores, S. M. (2009). State DREAM acts: The effect of in-state resident tuition policies and undocumented Latino students. The Review of Higher Education, 33(2), 239283. https://doi.org/10.1353/rhe.0.0134

Flores, S. M., \& Chapa, J. (2009). Latino immigrant access to higher education in a bipolar context of reception. Journal of Hispanic Higher Education, 8(1), 90-109. https://doi.org/10.1177/1538192708326996

Flores, S. M., \& Drake, T. A. (2014). Does English language learner (ELL) identification predict college remediation designation?: A comparison by race and ethnicity, and ELL waiver status. The Review of Higher Education,38(1), 1-36. https://doi.org/10.1353/rhe.2014.0041

Flores, S. M., \& Horn, C. L. (2010). College persistence among undocumented students at a selective public university: A quantitative case study analysis. Journal of College Student Retention: Research, Theory \& Practice, 11(1), 57-76. https://doi.org/10.2190/cs.11.1.d

Flores, S., \& Southern, K. G. (2010). Citizenship, college degrees, and occupational outcomes: Comparison of Latino immigrants and U.S. natives at the turn of the century. Journal of Hispanic Higher Education, 9(1), 22-42. https://doi.org/10.1177 $/ 1538192709352245$

Freeman, E. (2017). Diversion or democratization: Do rural, Hispanic, community college students show signs of academic undermatch? Journal of Hispanic Higher Education, 16(1), 77-97. https://doi.org/10.1177/1538192716628604

Garcia, L. M., \& Bayer, A. E. (2005). Variations between Latino groups in U.S. Postsecondary educational attainment. Research in Higher Education, 46(5), 511-533. https://doi.org/10.1007/s11162-005-3363-5

Garibay, J. C., Herrera, F. A., Johnston-Guerrero, M. P., \& Garcia, G. A. (2015). Layers of influence: Exploring institutional- and state-level effects on college student views toward access to public education for undocumented immigrants. Research in Higher Education, 57(5), 601-629. https://doi.org/10.1007/s11162-015-9400-0

Gonzalez, K. P., Stoner, C., \& Jovel, J.E. (2003). Examining the role of social capital in access to college for Latinas: Toward a college opportunity framework. Journal of Hispanic Higher Education, 2(1), 146-170. https://doi.org/10.1177 $/ 1538192702250620$ 
Griffin, K., Pilar, W. D., Mcintosh, K., \& Griffin, A. (2012). "Oh, of course I'm going to go to college:" Understanding how habitus shapes the college choice process of Black immigrant students. Journal of Diversity in Higher Education,5(2), 96-111. https://doi.org/10.1037/a0028393

Griffin, K. A., Cunningham, E. L., \& George Mwangi, C. A. (2016). Defining diversity: Ethnic differences in Black students' perceptions of racial climate. Journal of Diversity in Higher Education,9(1), 34-49. https://doi.org/10.1037/a0039255

Herrera, F. A., Garibay, J. C., Garcia, G. A., \& Johnston, M. P. (2013). Documenting attitudes toward undocumented immigrant access to public education: A multilevel analysis. The Review of Higher Education, 36(4), 513-549. https://doi.org $/ 10.1353 /$ rhe.2013.0043

Hope, E. C., Keels, M., \& Durkee, M. I. (2016). Participation in Black Lives Matter and deferred action for childhood arrivals: Modern activism among Black and Latino college students. Journal of Diversity in Higher Education,9(3), 203-215. https://doi.org/10.1037/dhe0000032

Inkelas, K. K. (2003). Diversity's missing minority: Asian Pacific American undergraduates' attitudes toward affirmative action. The Journal of Higher Education, 74(6), 601-639. https://doi.org/10.1080/00221546.2003.11780861

Jauregui, J. A., \& Slate, J. R. (2010). Texas borderland community colleges and views regarding undocumented students: A qualitative study. Journal of College Student Retention: Research, Theory \& Practice, 11(2), 183-210. https://doi.org $/ 10.2190 / \mathrm{cs} .11 .2 . \mathrm{b}$

Kim, E. (2014). When social class meets ethnicity: College-going experiences of Chinese and Korean immigrant students. The Review of Higher Education,37(3), 321-348. https://doi.org/10.1353/rhe.2014.0015

Kim, E., \& Diaz, J. (2013). Immigrant students and higher education. ASHE Higher Education Report, 38(6). Jossey-Bass.

Kim, J. (2003). Returns to college education: An analysis of Hispanic workers. Journal of Hispanic Higher Education, 2(3), 276-291. https://doi.org/10.1177 /1538192703002003005

Kim, J. (2009). Administering and assessing culture-specific interventions to address culture-bound issues among Asian American college students. New Directions for Institutional Research, 142, 27-39. https://doi.org/10.1002/ir.294

Kouyoumdjian, C., Guzmán, B. L., Garcia, N. M., \& Talavera-Bustillos, V. (2017). A community cultural wealth examination of sources of support and challenges among Latino first-and second-generation college students at a Hispanic serving institution. Journal of Hispanic Higher Education, 16(1), 61-76. https://doi.org/10.1177/1538192715619995

Laanan, F. S., \& Starobin, S. S. (2004). Defining Asian American and Pacific Islanderserving institutions. New Directions for Community Colleges, 127, 49-59. https://doi.org/10.1002/cc.163 
Lauby, F. (2017). "Because she knew that I did not have a social:" Ad hoc guidance strategies for Latino undocumented students. Journal of Hispanic Higher Education, 16(1), 24-42. https://doi.org/10.1177/1538192715614954

Leinbach, D. T., \& Bailey, T. R. (2006). Access and achievement of Hispanics and Hispanic immigrants in the City University of New York. New Directions for Community Colleges, 133, 27-40. https://doi.org/10.1002/cc.225

Luna, V., \& Prieto, L. (2009). Mentoring affirmations and interventions: A bridge to graduate school for Latina/o students. Journal of Hispanic Higher Education, 8(2), 213-224. https://doi.org/10.1177/1538192709331972

Madrigal-Garcia, Y. I., \& Acevedo-Gil, N. (2016). The new Juan Crow in education: Revealing panoptic measures and inequitable resources that hinder Latina/o postsecondary pathways. Journal of Hispanic Higher Education, 15(2), 154-181. https://doi.org/10.1177/1538192716629192

Mahaffy, K. A., \& Pantoja, C. (2012). Latina/o students' needs. Journal of College Student Retention: Research, Theory \& Practice, 14(3), 359-370. https://doi.org /10.2190/cs.14.3.e

Maramba, D. C., \& Museus, S. D. (2012). Examining the effects of campus climate, ethnic group cohesion, and cross-cultural interaction on Filipino American students' sense of belonging in college. Journal of College Student Retention: Research, Theory \& Practice, 14(4), 495. https://doi.org/10.2190/cs.14.4.d

Maxwell, J. (2005). Qualitative research: An interactive design. (2nd ed). Thousand Oaks, CA: Sage.

McLaughlin Gonzales, L., \& Raymond Ting, S. (2008). Adjustment of undergraduate Latino students at a southeastern university: Cultural components of academic and social integration. Journal of Hispanic Higher Education, 7(3), 199-211. https://doi.org/10.1177/1538192708317117

Mendez, J. J., \& Cabrera, N. L. (2015). Targets but not victims: Latina/o college students and Arizona's racial politics. Journal of Hispanic Higher Education, 14(4), 377-391. https://doi.org/10.1177/1538192715575371

Morales, A., Herrera, S., \& Murry, K. (2011). Navigating the waves of social and political capriciousness: Inspiring perspectives from DREAM-eligible immigrant students. Journal of Hispanic Higher Education, 10(3), 266-283. https://doi.org/10.1177/1538192708330232

Morales, E. E. (2009). Legitimizing hope: An exploration of effective mentoring for Dominican American male college students. Journal of College Student Retention: Research, Theory and Practice, 11(3), 385-406. https://doi.org/10.2190/cs.11.3.e

Muñoz, L. (2012). Exploring the meaning of civic engagement in the United States: Mexican immigrants in central Texas. New Directions for Adult and Continuing Education, 135, 33-40. https://doi.org/10.1002/ace.20024 
Museus, S. D., \& Maramba, D. C. (2011). The impact of culture on Filipino American students' sense of belonging. The Review of Higher Education,34(2), 231-258. https://doi.org/10.1353/rhe.2010.0022

Nienhusser, H. K. (2014). Role of community colleges in the implementation of postsecondary education enrollment policies for undocumented students. Community College Review, 42(1), 3-22. https://doi.org/10.1177 /0091552113509837

Nienhusser, H. K. (2015). Undocumented immigrants and higher education policy: The policymaking environment of new york state. The Review of Higher Education,38(2), 271-303. https://doi.org/10.1353/rhe.2015.0006

Nuñez, A. (2009). A critical paradox? Predictors of Latino students' sense of belonging in college. Journal of Diversity in Higher Education, 2(1), 46-61. https://doi.org/10.1037/a0014099

Nuñez, A., \& Kim, D. (2012). Building a multicontextual model of Latino college enrollment: Student, school, and state-level effects. The Review of Higher Education,35(2), 237-263. https://doi.org/10.1353/rhe.2012.0004

O'Connor, N., Hammack, F. M., \& Scott, M. A. (2009). Social capital, financial knowledge, and Hispanic student college choices. Research in Higher Education, 51(3), 195219. https://doi.org/10.1007/s11162-009-9153-8

Oseguera, L., Denson, N., \& Hurtado, S. (2008). Hispanic students and the Gates Millennium Scholarship program: Promising results extending to the third college year. Journal of College Student Retention: Research, Theory \& Practice, 10(3), 307-338. https://doi.org/10.2190/cs.10.3.d

Pak, C. S. (2018). Linking service-learning with sense of belonging: A culturally relevant pedagogy for heritage students of Spanish. Journal of Hispanic Higher Education, 17(1), 76-95. https://doi.org/10.1177/1538192716630028

Passel, J. S., \& Cohn, D. V. U. S. (2008). US population projections: 2005-2050. Retrieved from: https://scholar.google.com/scholar?hl=en\&as_sdt=0\%2C22\&q $=$ Passel $+\% 26+$ Cohn $\% 2 \mathrm{C}+2008 \&$ btnG $=$

Pena, M., Hernandez, E. I., Sotello Viernes Turner, C., Dirks, D. (2007). Balancing school with the call to community service: Hispanic master's students in U.S. theological schools. Journal of Hispanic Higher Education, 6(3), 284-296. https://doi.org/10.1177/1538192707302957

Perez, W., Espinoza, R., Ramos, K., Coronado, H., \& Cortes, R. (2010). Civic engagement patterns of undocumented Mexican students. Journal of Hispanic Higher Education, 9(3), 245-265. https://doi.org/10.1177/1538192710371007

Person, D., Gutierrez Keeton, R., Medina, N., Gonzalez, J., \& Minero, L. P. (2017). Effectively serving AB 540 undocumented students at a Hispanic serving institution. Journal of Hispanic Higher Education, 16(3), 256-272. https://doi.org/10.1177/1538192716628956 
Person, A. E., \& Rosenbaum, J. E. (2006). Chain enrollment and college enclaves: Benefits and drawbacks of Latino college students' enrollment decisions. New Directions for Community Colleges, 133, 51-60. https://doi.org/10.1002/cc.227

Portes, A., \& Fernández-Kelly, P. (2008). No margin for error: Educational and occupational achievement among disadvantaged children of immigrants. The annals of the American academy of political and social science, 620(1), 12-36. https://doi.org/10.1177/0002716208322577

Pyne, K. B., \& Means, D. R. (2013). Underrepresented and in/visible: A Hispanic firstgeneration student's narratives of college. Journal of Diversity in Higher Education,6(3), 186-198. https://doi.org/10.1037/a0034115

Riegle-Crumb, C. (2010). More girls go to college: Exploring the social and academic factors behind the female postsecondary advantage among Hispanic and white students. Research in Higher Education, 51(6), 573-593. https://doi.org/10.1007/s11162-010-9169-0

Rudolph, B., Chavez, M., Quintana, F., \& Salinas, G. (2011). Filial responsibility expectations among Mexican American undergraduates: Gender and biculturalism. Journal of Hispanic Higher Education, 10(3), 168-182. https://doi.org/10.1177/1538192710397732

Sanchez, D. (2013). Racial and ego identity development in Black Caribbean college students. Journal of Diversity in Higher Education, 6(2), 115-126. https://doi.org/10.1037/a0031684

Smith, R. A. (2010). Feeling supported: Curricular learning communities for basic skills courses and students who speak English as a second language. Community College Review, 37(3), 261-284. https://doi.org/10.1177/0091552109356592

Southern, K. G. (2016). Institutionalizing support services for undocumented students at four-year colleges and universities. Journal of Student Affairs Research and Practice, 53(3), 305-318. https://doi.org/10.1080/19496591.2016.1143832

Stebleton, M. J., \& Aleixo, M. B. (2015). Examining undocumented Latino/a student interactions with faculty and institutional agents. Journal of Hispanic Higher Education, 14(3), 256-273. https://doi.org/10.1177/1538192715574097

Sullivan, K. T., Ramos-Sánchez, L., \& Mclver, S. D. (2007). Predicting the use of campus counseling services for Asian/Pacific Islander, Latino/Hispanic, and White students: Problem severity, gender, and generational status. Journal of College Counseling, 10(2), 103-116. https://doi.org/10.1002/j.2161-1882.2007.tb00011.x

Sy, S. R., \& Romero, J. (2008). Family responsibilities among Latina college students from immigrant families. Journal of Hispanic Higher Education, 7(3), 212-227. https://doi.org/10.1177/1538192708316208

Tauriac, J. J., \& Liem, J. H. (2012). Exploring the divergent academic outcomes of U.S.origin and immigrant-origin Black undergraduates. Journal of Diversity in Higher Education,5(4), 244-258. https://doi.org/10.1037/a0030181 
Teranishi, C. S. (2007). Impact of experiential learning on Latino college students' identity, relationships, and connectedness to community. Journal of Hispanic Higher Education, 6(1), 52-72. https://doi.org/10.1177/1538192706294946

Thorstensson Davila, L. (2008). Language and opportunity in the "land of opportunity:" Latina immigrants' reflections on language learning and professional mobility. Journal of Hispanic Higher Education, 7(4), 356-370. https://doi.org/10.1177/1538192708321652

Tierney, W. G. (2013). Life history and identity. The Review of Higher Education, 36(2), 255-282. https://doi.org/10.1353/rhe.2013.0006

Torraco, R. J. (2005). Writing integrative literature reviews: Guidelines and examples. Human Resource Development Review, 4(3), 356-367. https://doi.org/10.1177/1534484305278283

Torraco, R. J. (2016). Writing integrative reviews of the literature: Methods and Purposes. International Journal of Adult Vocational Education and Technology, 7(3), 62-70. https://doi.org/10.4018/ijavet.2016070106

Uy, P. S., Kim, S. J., \& Khuon, C. (2016). College and career readiness of Southeast Asian American college students in New England. Journal of College Student Retention: Research, Theory \& Practice. https://doi.org/10.1177/ 1521025116678852

Whittemore, R., \& Knafl, K. (2005). The integrative review: Updated methodology. Journal of Advanced Nursing, 52(5), 546-553. https://doi.org/10.1111/j.13652648.2005.03621.x

Wolf, D. S., Sax, L., \& Harper, C. E. (2009). Parental engagement and contact in the academic lives of college students. Journal of Student Affairs Research and Practice,46(2), 325-358. https://doi.org/10.2202/1949-6605.6044

Wrigley, H. S., Chen, J., White, S., \& Soroui, J. (2009). Assessing the literacy skills of adult immigrants and adult English language learners. New Directions for Adult and Continuing Education, 121, 5-24. https://doi.org/10.1002/ace.321

\section{Author Contact}

Chrystal A. George Mwangi, cgeorgem@gmu.edu

George Mason University, Higher Education Program

4400 University Drive, Enterprise Hall 310

Fairfax, VA 22030

Koboul Mansour, kemansour@umass.edu

Mujtaba Hedayet, mhedayet@umass.edu

University of Massachusetts Amherst

Department of Educational Policy, Research, and Administration

813 N. Pleasant Street, 174 North Furcolo Hall

Amherst, MA 01003 